\title{
REDEFINING AUSTRALIAN LANGUAGE CLASSROOM EFFECTIVITY: TOWARDS INTERCULTURAL COMPETENCE IN FOREIGN LANGUAGE LEARNING
}

\author{
Devina \\ Language Center, Bina Nusantara University, Jakarta, Indonesia, 11480 \\ devina@binus.edu \\ Rahmi Yulia Ningsih \\ Language Center, Primary Teacher Education, Bina Nusantara University, Jakarta, \\ Indonesia, 11480 \\ rahmi.ningsih@binus.edu \\ Lifia Yola Febrianti \\ Language Center, Industrial Engineering Department, Bina Nusantara University, \\ Jakarta, Indonesia, 11480 \\ lifia.febrianti@binus.ac.id
}

Accepted: 2020-07-01 , Approved: 2020-07-07 , Published: 2020-07-20

\section{ABSTRACT}

Global competence has inevitably expanded the way of education conducted in recent year. One key aspect of global competence is the emergence of cultural intelligence in the classroom - as one medium of global competence transfer is through language learning. Interest to learning a foreign language raises in which many people see foreign language learning as the window and door to the world. This paper aims at exploring global competence is delivered and conducted in a Spanish classroom in Brisbane, Australia. Data were gathered through (1) classroom observation (2) questionnaire distributed to the learner and (3) interview with the learners. Finding shows that in the program is perceived as effective and teacher holds the most important factor in the classroom. In addition to being knowledgeable and skillful, a teacher who possesses cultural intelligence is likely to be preferred. Classroom is portrayed as a hub for transfer of knowledge, allowing learners to bring their identity inside the class while learning being exposed to other foreign language.

Keywords: global competence, cultural intelligence, foreign language learning.

\section{INTRODUCTION}

The 21 st century learning puts

learning axis into global competence

in which it develops and expands

skills of the graduates (learner) to adapt with the advanced communities. Features and elements of key competence for graduates has allowed individual to expand themselves in many aspects. This 
contributes to an advanced society who are likely possess things that might not be look at deeply in the past decades. Such qualities require indivdiduals to be savvy at economic, cultural, environmental, and technological aspects (Mansilla and Jackson, 2011). Defined as the competence to be possessed by recent graduates, global competence requires learner to expand their skills in four domains elements: 1) the ability to investigate the world, 2) the ability to acknowledge perspectives, 3) the ability to communicate ideas, and 4) the ability to take action (Mansilla and Jackson, 2011).

Cultural intelligence, also known as Cultural Quotient (CQ) is defined as the ability of a person to well-respond and act appropriate and effectively in multicultural and diverse situations (Kuhle, 2018). Moreover, it serves to define the human ability to comprehend and respond appropriately in any given cross-cultural and multicultural situations. The intelligence arises as an individual interacts from different cultures and customs, that in some sense, the intelligence indicates appropriate attitude toward cultural differences. Two branch of understanding $\mathrm{CQ}$ is defined from "general intelligence hypothesis" and "social intelligence hypothesis" (Kuhle, 2018, p. 2), in which both consider the notion of human behavior.

In foreign language study, CQ has been critically taken into account for both language learning and teaching. Although it does not originally come from foreign or second language study area, CQ shifts and expands the notion of foreign language learning and the way foreign language has been taught over the years. Kramsch (2014) identified that changes of the notion occur for the 
learning outcomes, as the goal of learing does not merely lie on having or becoming native-like speaker, but rather becoming an 'intercultural speaker'. On the topic of 'intercultural speaker', it is further suggested that being an intercultural speaker has the same goal to be able to adapt to differences as $\mathrm{Ng}$ (2013) put as the capability of a learner to understand the target language (TL) language and culture, whilst developing the sense of critical awareness in regard to the language the learners study. CQ would be different with emotional intelligence (EQ), in which the notion of CQ has changed language learning to be seen and interpreted, that from merely understanding or speaking other language, CQ has taken the learners of foreign language to be (1) able to speak the TL and (2) able to adjust cultural differences in a various multicultural and/or cross-cultural context.
The most advanced and deepest definition from both ethnography and anthropology study area may define culture as a "way of life" (Highmore, 2016, p.3). The definition sees that people may value other's cultural background, beliefs on a certain value, attitudes towards a condition, and practices from several ideas, further, foreign language interprets culture as the ability to see a person and other's identity through many shades, layers, and perspectives. This definition brings into account that understand one's position from many angles hold the most important idea in CQ.

Further, towards $\mathrm{CQ}$ in language learning Liddicoat and Scarino (2013) addressed three important elements of language; language as a structural system, language as communicative system, and language as social practices. They also pointed out that language 
teaching needs to be fairly reach each element accordingly. Thus, language teaching should evaluate, take, and embed the idea of structural, communicative, and social as its final product. When Bryam (2002) emerged with the idea of cultural intelligence, he addressed that learning foreign language aims for engaging learner with both usual and typical values, norms, beliefs and attitudes of the experience from the target language. It is clearly pictured again that language teaching should allow space for elevating differences from the learner's original cultural background with the target language s/he learns.

Such high interest in CQ towards language learning results in pedagogy of language learning. One of the most well-known pedagogy of intercultural language learning (ICC) five saviors are suggested as the outcomes of the competence. They are; savoirs, savoir comprende, savoir apprende or faire, savoir s'engager, and savoir etre (Bryam, 2002). Savoir etre aims for being curious and open, which looks learners to always question and justify one self's cultural beliefs. Savoir s'engager sees at the learners capability to assess prespective and points of view crticially. Savoirs puts its concern on the way a single person understand culture embedded to their own while also considering others'. Further, savoir comprende has the focus to understand, give explanation and notic vertain values and beliefs of oneself and other people. Savoir apprende/faire concerns with the idea to grasp and respond the knowledge that has been update in one's practical and real life.

What makes the pedagogy challenging is when limitation happens for the learning materials or sources, especially for foreign 
language classroom not in their country of origin. Perhaps it's worth to see the further exploration of combining topic-based curriculum with CQ (Meiki, 2010). The research takes Cross-cultural Communication (CCC) course into discussion. It is known that confusion within the course occur as teachers are not sure the extent what information to be include and not include in the topic of cross-cultural communication, and which English culture should they refer to (U.K., U.S., or any other countries). Finding shows several topics to be implemented along the course are; custom in dating, custom for working, custom for identity and individuality, custom for events such as funeral, and custom between men and women. The class is labelled as "interesting" by the participants for allowing them to be indulged with the culture of Japan.

Soon as an institution has developed their ICC curriculum, the institutions needs to prepare the community of the protocol for mixed of students to how it may support or bridge differences. Another worth to note study was done by O'Leary, Shapiro, Toma, Sayson, LevisFitzgerald et al (2020), addressing the idea of embracing diversity in science, technology, engineering, and mathematics (STEM) learning. Such focus is given to explore instructor indentities, learning obstacles, and mindset. It is further found out that through cultural workshop, STEM class increased teachers' competency and knowledge in social identities, changed their mindset from fixed into adaptive, and adjusted teaching methodology in regard to cultural intelligence.

The studies pointed out out what at stake with global competence in education nowadays. Addressing at the importance of it, however, the 
studies do not look at what should teacher have (attitudes, traits, practices) and provide to learning towards the global competence. Evaluating and considering the condition that global competence with ICC have emerged into foreign language teaching, this study would like to answer the following research questions:

1. To what extent foreign language learning may take and bring learner's potential in this global society?

2. How does learner perceive the notion of successful foreign language program towards global competence?

\section{METHOD}

The research method would cover five discussion ideas; data collection, respondents, instruments, procedures, and data analysis.

Firstly, this study is conducted in Brisbane, Australia to one of the well-known foreign language classroom. The languge classroom is a private institution offering Spanish classes for general purposes. Some learners are university students and workers. The study is conducted in one session by also allowing chances for interview with the teacher and questionnaire to the students. The data is collected through three approaches;

(1) classroom observation,

questionnaire for learners and (3) interview with the learners. In the first phase, classroom observation was conducted. There is an audio recording during the session, resulting in excerpt of classroom observation. The classroom observation was done for one evening session. The idea of classroom observation was to gain the idea how classroom interaction may occur between teacher to student, and student to student. Further, questionnaire is distributed to know 
the perception of the classroom. And lastly, a deeper interview to several selected learners.

Next, The respondents are 35 students those who are both currently taking the course and has completed their study there. This also includes the teacher and student for one-time classroom observation. The instrument used in the study is audio recorder, journal reflection, and online questionnaire.

Finally, the data was analyzed by looking at its concordance with the idea of global competence. The chart of data analysis is provided as follows. 

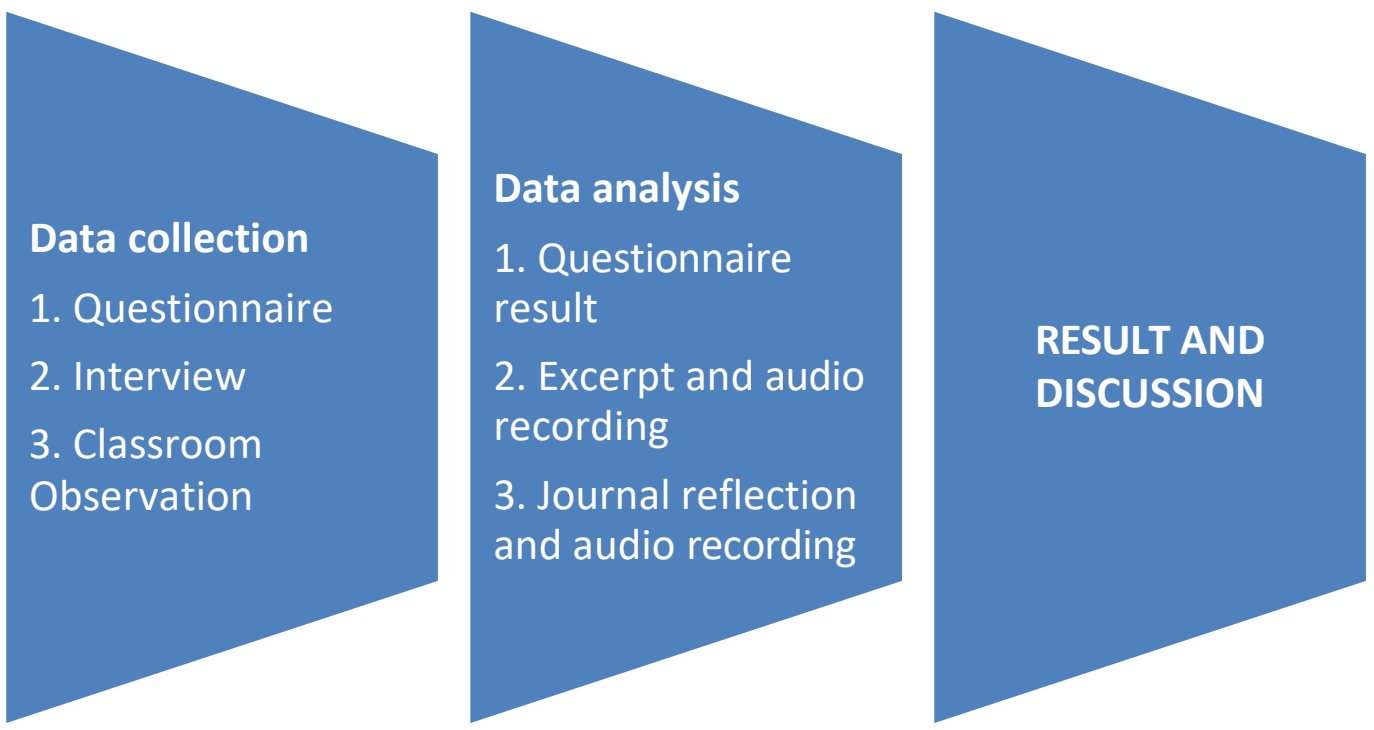

Figure 1. Research methodology

\section{RESULTS AND DISCUSSION}

The result and discussion bring

participants puts "travel" for their

two major explanations to answer the

sole reason taking the class.

research questions as follows.

During the first week of the class, teacher asks students on their

1. To what extent foreign language learning may take and bring learner's potential in this global society?

The idea that foreign language takes and opens doors to the world may be suitable for this context. The greatest and highest motivation for learning is found to be travelling purposes. Questionnaire reveals that $68,6 \%$ motivation for taking the lesson. Traveling purpose holds the highest interest for learning, furthermore, it is also acknowledged that some of the learners would like to take Spanish as their second language for these reasons; pure interest in the language $(17,4 \%)$; study purpose $(8,6 \%)$ work purpose $(5,7 \%)$ make friends $(2.9 \%)$ and having

BAHTERA : Jurnal Pendidikan Bahasa dan Sastra, Volume Juli 2020 
distant family or relatives from

Spanish $(2,9 \%)$.

The above data presents that

all learners have one goal of

taking the class. For teachers to

know the motiviation of learners

could be beneficial as teacher may

relate and note things during learning that might help students

more. Such condition might

happens from the following

classroom observation excerpt

amid discussing about national

event "Dia de Muertos" to the

student who would like to take a

further study to Mexico.

\begin{tabular}{|l|l|}
\hline Student A & :"Does Dia de Muertos stand for Halloween?" \\
\hline Teacher & $\begin{array}{l}\text { : Not really, the date might be close between the two occasions, but } \\
\text { "Dia de Muertos" is celebrating the dead, our ancestors that... they } \\
\text { with us for that day. It's a very important thing in Mexico because } \\
\text { it's... take the idea of having the spririt of the deceased relatives and } \\
\text { families. And they're with you at that time. Um, when you take your } \\
\text { study in Puebla, you will see that on that day everything is going to be } \\
\text { very festive. It...it's like a party and and huge celebration. So it's the } \\
\text { day for the dead, celebrate it and be happy about it". }\end{array}$ \\
\hline
\end{tabular}

Table 1. Excerpt from classroom observation

The way teacher provide

explanation, by correlating it to the

future event contributes to a high

motivation for learners to

understand more about the culture

and how Spanish speaker relates to

their cultural background (i.e., Dia

de Muertos). The classroom

observation also shows that

teacher have a very positive

attitude towards the native languge he's speaking. Positive atitudes

from the teacher allow student to see what does the event Dia de Muertos is perceived by the local people - that is a day for celebrating, not a day for sorrow.

This brings into the discussion that teacher's attitude towards cultural understanding holds an important role. It's also worth to note that it's not merely on the 
understanding on the language, but more importantly, how teacher explains such differences and makes it as the bridge from the two culture.

2. How does learner perceive the notion of effective foreign language program towards global competence?

The overall scale average of course effectiveness shows that the course is effective language development in related to how they value their development regarding the value of global competence. Likert scale shows that rating for course efficiency is 4.7 (out of 5), with the distributions 1: not effective, 2: less effective, 3: effective enough, 4: effective, 5: very effective

Questions: Rate the quality of this course as it contributed to your Spanish language skills.

\section{Likert Scale on the Course Effectiveness}

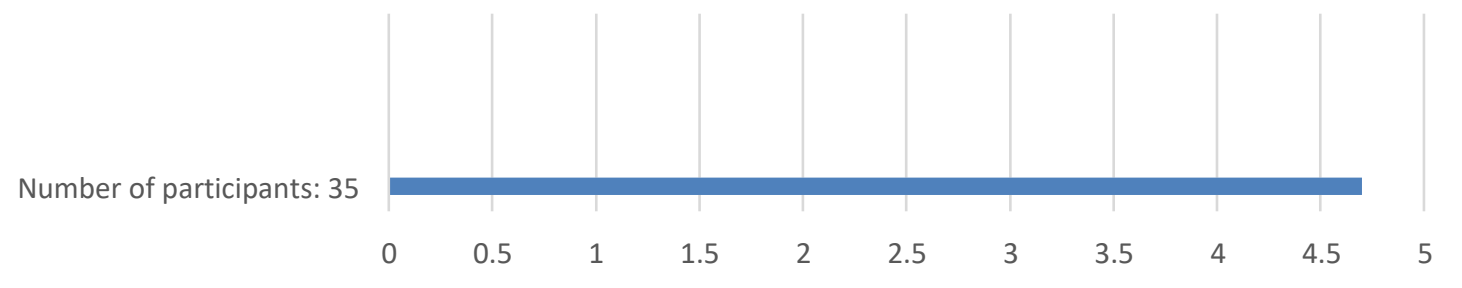

Figure 2. Likert scale on the course effectiveness

The above data shows that almost all learners agree that the course is effective. Finding shows that there're several reasons that learners take into consideration while evaluating the course. The data is provided as follows 
Question: What do you like the most in regard to this course?

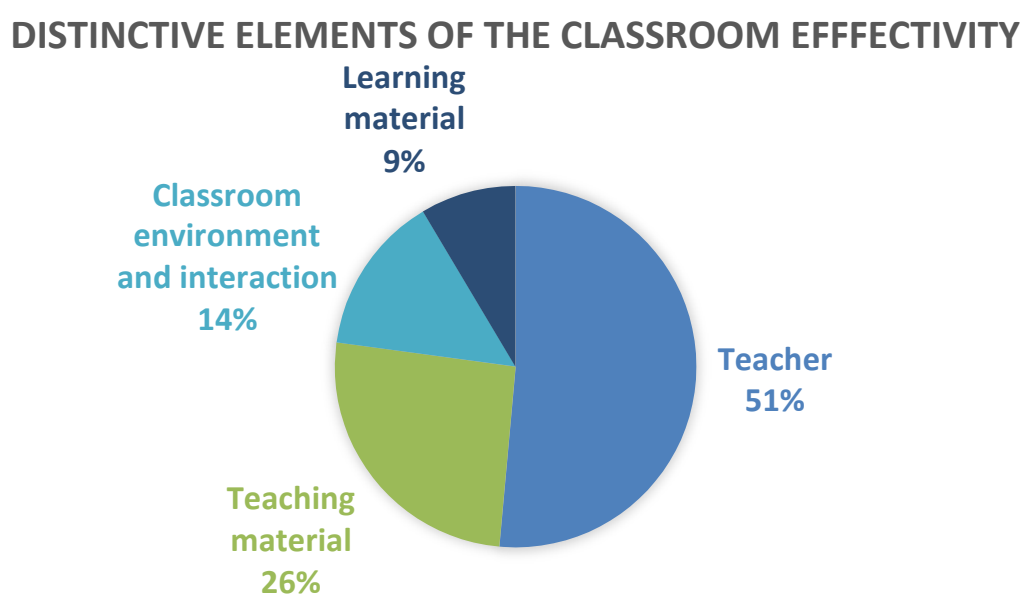

Figure 3. Distinctive elements of the classroom effectivity

As the classroom is found out to be effective (4.7 out of 5$)$, reasons for the classroom effectivity is found out to be based on the: teacher $(51 \%)$, teaching material $\quad(26 \%), \quad$ classroom environment and interaction (14\%), and learning material (9\%). It is worth to note that teacher holds the highest elements among other considerations. A deeper interview regarding this what features that the teacher possess evokes that such features are; the teacher's ability to perform teaching; classroom management; and cultural intelligence becomes the fundamental reason. As one student note regarding the teacher's teaching methodology "I believe that my teacher who made our time in the class of a very high standard and quality. The content was challenging, but his explanations allowed me to understand the content. I would happy continue learning Spanish with him in the future because of the effort he puts into each lesson" - Student E.

The ability for the teacher to make things practical makes what 
it's worth. The teacher also allows

a great classroom management to occur, as another student put, "The ability of the teacher to facilitate various ways of learning the class material,

e.g. role play, class games". -

\section{Student J}

Particularly in regard to the cultural intelligence, student B put that the teacher's attitude allows a "friendly discussion and open learning environment", in which he feels "learning the language together with the teacher, not learning with someone who knows anything". The same conclusion is also portrayed by student I it is noted that "the teacher makes me comfortable to explore my Spanish, the teacher has the personal touch to make many students easily understand and cooperate with". The idea of the ability to grasp other cultural values is provided by student A “...(teacher) makes learning fun, adding humorous story, and especially when he the cultural experience of Mexico. Another student points out that "opens my minds that teacher gives many story and values not only in Mexico but other culture around the world, he is a master!”.

An effective language classroom in this global and/or intercultural competence would like to take and will revolve around how a single class may open the eyes of the learners. It is the way of delivery in which teacher acts as the facilitator, and values that he brings to the classroom.

\section{CONCLUSION}

All in all, the study presents the idea the essence of global competence in foreign lagnauge classroom in Australia. The analysis presents several findings as follows.

Firstly, in global society, this 
research reveals that motivations for Spanish language classroom in Australia are mostly based on the willingness to see the world, or what is labelled as "travel" by the learners $(68 \%)$. This is inline with the idea of global competence that regarding the ability or willingness to investigate the world. To be exact, the other reasons for learning are as follows; pure interest in the language $(17,4 \%)$; study purpose $(8,6 \%)$ work purpose $(5,7 \%)$, making friends $(2.9 \%)$ and having distant family or relatives from Spanish (2,9\%).

Secondly, it is found out that teacher are likely to give insight and story of what lies behind particular cultural practices, in which it opens what Spanish speakers have. Learners, at the same time, study all the facts and grasp it - especially those who have the motivation for travelling - gain all the beneficial knowledge for their future plan.

Lastly, foreign language learning admittedly has provided such great knowledge in being the hub of world's knowledge. It is further noted that this study reveals learners to have a strong connection with the teacher as the teacher is considered to be culturally intelligent for teacher's attitudes, managing classroom of multicultural group in Australia, and teacher's broad knowledge on diverse cultural practices. All the aspects make the program is perceived as effective (the value of 4.7 out of 5). In then, an effective foreign language classroom in this global competence can be taken from the notion of having culturally intelligence teacher, that would transform the classroom into space for abundant chances for learning. 


\section{REFERENCES}

Bryam, M., Gribkova, B., \& Starkey, H. (2002). Developing the intercultural dimension in language teaching: A practical introduction for teachers. Council of Europe.

Center for Global Education. (2005).

What is global competence?

Asia Society.

https://asiasociety.org/educatio $\underline{\mathrm{n} / \text { what-global-competence }}$

Earley, P.C., \& Ang, S. (2003). Cultural intelligence: Individual interactions across cultures. Palo Alto, CA: Stanford University Press.

Highmore, B. (2016). Culture (1st ed.). London: Routledge.

Kramsch, C. (2013). Culture in foreign language teaching. Iranian Journal of Language Teaching Research, 1(1), 5778.

Kramsch, C. (2014). Language and culture. AILA Review, 27, 30-55. doi:10.1075/aila.27.02kra

Kuhle, A. (2018). (Dis)Continuity: The cultural intelligence hypothesis reconsidered. Language Sciences, 67, 59-71.

https://doi.org/10.1016/j.langsci.2 018.04 .001

Liddicoat, A. J., \& Scarino, A. (n.d.). Languages, cultures, and the intercultural. In Intercultural Language Teaching and Learning (pp. 11-30). doi:10.1002/9781118482070

Meiki, S. (2010). A topic-based syllabus for a cross-cultural communication course: The case of a university in Japan. Intercultural Communication Studies, 19(1), 119-213.

Mansilla, V. B., \& Jackson, A. (2011). Educating for global competence: Preparing our youth to engage the world. Asia Society. https://asiasociety.org/files/bo ok- globalcompetence.pdf

BAHTERA : Jurnal Pendidikan Bahasa dan Sastra, Volume Juli 2020 
BAHTERA: Jurnal Pendidikan Bahasa dan Sastra, Volume 19 Nomor 2 Juli 2020 http://journal.unj.ac.id/unj/index.php/bahtera/

P-ISSN : 0853-2710

E-ISSN : 2540-8968

Ng, R. (2013). Cultural intelligence.

In The Encyclopedia of Cross-

Cultural Psychology (pp. 1 -

4). John Wiley \& Sons, Inc.

https://doi.org/10.1002/97811183

39893.wbeccp130

O'Leary, E. S., Saphiro, C., Toma, S.,

Sayson, H. W., Levis-Fitzgerald,

M., Johnson, T., \& Sork, V. L.

(2020). Creating inclusive

classrooms by engaging STEM

faculty in culturally responsive

teaching workshops.

International Journal of STEM

Education, 7(32).

https://doi.org/10.1186/s40594-

020-00230- 7 